\title{
Facile fabrication of organobentonite-carboxymethyl chitosan hybrid film that absorbs organophosphate insecticides
}

\author{
DAU HUNG ANH ${ }^{1}$ and KANCHANA DUMRI ${ }^{2, *}$ \\ ${ }^{1}$ Biogreen Material Research and Service Co. Ltd., Chiang Mai 50140, Thailand \\ ${ }^{2}$ Department of Chemistry, Faculty of Science, Chiang Mai University, Chiang Mai 50200, Thailand \\ *Author for correspondence (kanchana.d@cmu.ac.th, kdumri@gmail.com)
}

MS received 12 October 2016; accepted 25 January 2017; published online 7 September 2017

\begin{abstract}
Organophosphate (OP)-insecticide-absorbing hybrid film containing $10 \%(\mathrm{w} / \mathrm{w})$ organobentonite and carboxymethyl chitosan $(\mathrm{CMCh})$ was fabricated and tested. Bentonite clay was modified to organobentonite by two steps modification with (1) $\mathrm{NaCl}$ and (2) plant alkaloid monovalent cation berberine. $\mathrm{CMCh}$ was synthesized from commercial shrimp chitosan. Afterwards, organobentonite was immobilized into CMCh matrix via in situ polymerization of CMCh to cast a hybrid film with $0.5 \mathrm{~mm}$ thickness. Scanning electron microscopy images of organobentonite powder and the film revealed the porous material and layer-upon-layer structure, respectively, which is supposed to enhance the water permeability of the film. Fourier transform infrared spectrometry analysis revealed similarly chemical characteristics of the CMCh component in the film and synthesized CMCh polymer powder. The film was then investigated to remove four OP insecticides including profenofos, chlorpyrifos, methyl parathion and dimethoate of $5 \mathrm{ppm}$ concentration in spiked water samples via batch filtration. High-pressure liquid chromatography analysis showed that the removal rates for profenofos, chlorpyrifos, methyl parathion and dimethoate after seven batches were 42, 39, 24 and 20\%, respectively. Hence, absorptivity of this film for tested OP insecticides was demonstrated. Furthermore, the combination of organobentonite and natural chitosan is promising for novel absorptive film material generation with regard to environmental clean-up study.
\end{abstract}

Keywords. Organobentonite; carboxymethyl chitosan; hybrid film; organophosphate insecticides; batch filtration.

\section{Introduction}

Bentonite clay and carboxymethyl chitosan $(\mathrm{CMCh})$ products are now commercialized world-wide and studied variously for environmental application. Bentonite is a well-known material for the development of environment clean-up techniques by its absorptivity for diverse materials from heavy-metal toxins, e.g., As (III), Cd (II), Cu (II, III), Ni (II) and Pb (II) [1-5], to agricultural herbicides and insecticides, e.g., atrazine, carbaryl, dichlovos, parathion, paraoxon [6-9], and hazardous polycyclic aromatic hydrocarbons, e.g. naphthalene, flouranthene, benzo[a]pyrene and benzo[a]anthracene $[10,11]$. For applications, bentonite can be chemically modified using a large selection of alkylammonium or quaternary ammonium cations, where these cations replace the interlaying inorganic cations in bentonite, e.g., $\mathrm{Ca}^{2+}$ and $\mathrm{Na}^{+}$, to form organobentonite. For example, bentonite types modified by plant alkaloid berberine (5,6-dihydro-9, 10dimethoxybenzo[g]-1,3 benzodioxolo[5,6-a]quinolizinium), tetradecyltrimethyl ammonium bromide, dodecyltrimethylammonium bromide or hexadecyl trimethyl ammonium and phenyltrimethylammonium increasingly absorb pesticides malathion and butachlor, herbicides terbuthylazine and diuron and industrial dyeing wastewater [12-15]. Among alkylammonium compounds, berberine is a selective candidate for bentonite modification, which is a major alkaloid from Coscinium fenestratum. This plant is being used to date as a traditionally pharmaceutical component in Asian countries, e.g., Thailand, Vietnam and China [16]. The incorporation of berberine into different clays via cation exchange mechanism has been reported $[14,17]$. It resulted in the expansion of the basal spacing in the clay structures, which increased the absorptivity of the modified clay for the target pollutants $[14,15]$. CMCh, a water-soluble derivative polymer from biological chitosan molecules with high water solubility, has found applications in pharmacy and cosmetics. The hydrogel form of $\mathrm{CMCh}$ has biocompatibility and biodegradability properties, which have been applied for drug delivery and wound healing $[18,19]$. CMCh also behaves as an antimicrobial and antioxidant agent and emulsion stabilizer, which makes it an applicable matrix for cosmetics.

Interestingly, the combination of organobentonite or bentonite and chitosan yields new absorptive material bionanocomposites, which can absorb various industrial dyes and herbicides, e.g., cationic Rhodamine 6G, anionic Amido Black 10B or Bezactiv Orange V-3R and clopyralid, in wastewater treatment [20-24]. These materials have higher absorptive capacity for target absorbate than that of either organobentonite or chitosan $[22,24]$. The chitosan-bentonite nanocomposites also show antibacterial activity (both Gram 
positive, e.g., Bacillus subtilis and Staphylococcus aureus, and Gram negative, e.g., Escherichia coli) as well as higher tensile strength in comparison with chitosan moiety $[25,26]$.

The organophosphate (OP) insecticides tested in this work were chlorpyrifos, profenofos, dimethoate and methyl parathion. They are classified into class II (moderately toxic) and class IA (extremely toxic) for inhalation and ingestion by WHO, respectively [27]. Agricultural-product-exporting countries, e.g., Thailand, use these OP insecticides but the control of use is always problematic; therefore, their residues can be detected ubiquitously not only in harvested products but also in nearby agricultural water zones or even in fresh water sources due to rainfall event $[28,29]$. Towards this end, we fabricated a film composed of berberine-modified bentonite and synthesized $\mathrm{CMCh}$. The film materials were tested to remove the four aforementioned OP insecticides in spiked water. The absorptivity of the film based on their structures and the interactions between film components and OP insecticides are described and discussed.

\section{Experimental}

\subsection{Materials}

The commercial bentonite or calcium bentonite (designated as bentonite) was purchased from Srichand United Dispensary Co., Ltd. (Bangkok, Thailand). Commercial grade shrimp chitosan of flake polymer type (molecular weight in the range 900-1,300 kDa) was purchased from Taming Enterprises (Samutsakon, Thailand).

All chemicals were of analytical grade. Berberine chloride $(98 \%$, designated as $\mathrm{BBrCl})$ and $\mathrm{OP}$ insecticides $(>97 \%$, PESTANAL ${ }^{\circledR}$, including methyl parathion, chlorpyrifos, profenofos and dimethoate, were purchased from Sigma and Riedel de Haen (Germany) (figure 1). Stock solutions (100 $\mathrm{mM})$ of insecticides were prepared in methanol $(\mathrm{MeOH})$ and kept at $4^{\circ} \mathrm{C}$ until further use. Working insecticide solutions were prepared at $5 \mathrm{ppm}$ in distilled water of $\mathrm{pH}$ 7.2.

\subsection{Two steps modification of commercial bentonite by $\mathrm{NaCl}$ and $\mathrm{BBrCl}$}

In the first step, bentonite was modified by $\mathrm{NaCl}$ to form $\mathrm{Na}-$ bentonite; $100 \mathrm{~g}$ of bentonite was well dispersed in 1 litre of $\mathrm{NaCl}(0.1 \mathrm{M}, \mathrm{pH} 7.5)$ and vigorously stirred at $600 \mathrm{rpm}$ for $8 \mathrm{~h}$ at room temperature. Afterwards, the reaction mixture was allowed to settle for $2 \mathrm{~h}$ and the supernatant was decanted. Later, the bentonite sediment was washed repeatedly 4-6 times by deionized water to eliminate the redundant $\mathrm{NaCl}$. Subsequently, $\mathrm{NaCl}$ residue in the supernatant was tested using a Chloride Low Range Test Kit, Model 8-P, Hach (USA). The bentonite sediment was dried at $95^{\circ} \mathrm{C}$ for $12 \mathrm{~h}$ and ground to powder afterwards. This was designated as Na-bentonite. In the second step, $30 \mathrm{~g}$ of Na-bentonite was re-dispersed in 1 litre of deionized water and $10 \mathrm{ml}$ homogeneous $\mathrm{BBrCl}$ solution $(0.3 \mathrm{~g} \mathrm{BBrCl}$ in $10 \mathrm{ml} \mathrm{MeOH})$ was

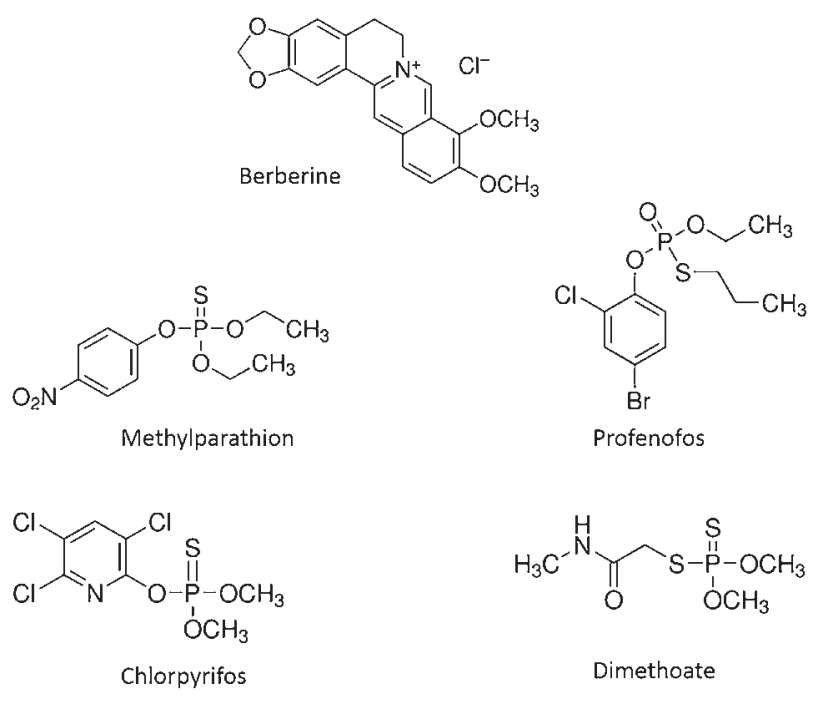

Figure 1. Structures of berberine chloride and tested OP insecticides.

pipetted step-wise ( $100 \mu \mathrm{l}$ in $10 \mathrm{~s})$ into the Na-bentonite mixture with vigorous stirring. Subsequently, the reaction mixture was stirred at $600 \mathrm{rpm}$ for $8 \mathrm{~h}$. The yellow sediment was allowed to settle within $2 \mathrm{~h}$, collected and dried at $95^{\circ} \mathrm{C}$ for $12 \mathrm{~h}$. The dried sediment was ground to powder and sieved using a 300-mesh sieve (Gallenkamp and Co, London). The latter was used for all insecticides absorption tests throughout this work and it was designated as BBr-bentonite. Both $\mathrm{Na}$-bentonite and $\mathrm{BBr}$-bentonite are generally designated as modified bentonite in all following contexts.

\subsection{Synthesis of $C M C h$}

CMCh was synthesized by the procedure of Chen and Park [33]. The chitosan powder (25 g) was suspended in a solution of $\mathrm{NaOH}: i$-propanol: $\mathrm{H}_{2} \mathrm{O}(1: 8: 2)$ and stirred at room temperature for $1 \mathrm{~h}$. The appropriate amount of monochloroacetic acid was added into the mixture and continuously stirred for $30 \mathrm{~min}$. The mixture was covered with an aluminium foil and placed in an oven at $50^{\circ} \mathrm{C}$ for $4 \mathrm{~h}$. Later, it was separated into liquid and solid phases. The solid phase was further suspended in $\mathrm{MeOH}$ and neutralized with glacial acetic acid. Subsequently, it was filtered and washed 5 times with ethanol $(70 \% \mathrm{v} / \mathrm{v} \mathrm{EtOH})$ to remove undesirable products and the last time with absolute $\mathrm{MeOH}$. The final product, designated as $\mathrm{CMCh}$, was dried in the oven at $50^{\circ} \mathrm{C}$ for $18 \mathrm{~h}$ and kept in a sealed polyethylene bag until further use.

\subsection{Casting of hybrid film containing organobentonite and CMCh}

Modified bentonite ( $2 \mathrm{~g}, \mathrm{BBr}$-bentonite and Na-bentonite) was firstly added step-wise $(50 \mathrm{mg}$ in $10 \mathrm{~s}$ ) into $500 \mathrm{ml}$ distilled water at $80^{\circ} \mathrm{C}$ under $500 \mathrm{rpm}$ stirring in a 1-litre glass beaker until a homogeneous grey suspension solution ( $\mathrm{Na} /$ bentonite) or yellow suspension solution (BBr/bentonite) was formed. 
Afterwards, $20 \mathrm{~g}$ of CMCh was added step-wise (50 mg in $10 \mathrm{~s}$ ) into the above suspension solution while the temperature was maintained at $80^{\circ} \mathrm{C}$; it was still under vigorous stirring until the polymerization of $\mathrm{CMCh}$ occurred and a homogeneous sticky grey or yellow suspension solution was formed; $100 \mathrm{ml}$ of the latter was poured into a $30 \mathrm{~cm} \times 15 \mathrm{~cm} \times 2 \mathrm{~cm}$ transparent acrylic tray and kept at $25^{\circ} \mathrm{C}$ for $72 \mathrm{~h}$ to form a film with approximate thickness of $0.5 \mathrm{~mm}$. These modified bentonite-CMCh films were designated as BBr-bentonite$\mathrm{CMCh}$ and Na-bentonite-CMCh films.

\subsection{Characterization of modified bentonites and modified bentonite-CMCh films by scanning electron microscopy}

The morphologies of modified bentonite and modified bentonite-CMCh films were characterized by scanning electron microscopy (SEM; JEM 5910 LV and JEM 1010 JOEL Ltd., Japan) at accelerating voltage of $15 \mathrm{kV}$ and fit magnification.

\subsection{Characterization of modified bentonites and modified bentonite-CMCh films by Fourier transform infrared spectrometry}

Chemical components of modified bentonite were identified by Fourier transform infrared spectrometry (FTIR) using a Bruker Tensor 27 (Bruker, USA) spectrometer. Samples were dried at $100^{\circ} \mathrm{C}$ overnight, ground mildly with $\mathrm{KBr}$ powder and subsequently pressed to form a disk, which was analysed further in the apparatus. For modified bentonite-CMCh films, the film materials were cut into $5 \mathrm{~mm} \times 5 \mathrm{~mm}$ square pieces and placed on $\mathrm{KBr}$ plates for analysis.

\subsection{Batch filtration to remove OP insecticides using modified bentonite-CMCh films}

Modified bentonite-CMCh films were cut into round pieces of $\varnothing 6 \mathrm{~cm}$ and 10 pieces were piled (approximately $10 \mathrm{~g}$ of film material) on the metal net bottom $(1 \mathrm{~mm} \times 1 \mathrm{~mm}$ mesh netting) of an acrylic column $(\varnothing 6 \mathrm{~cm} \times 20 \mathrm{~cm})$. One upper net was finally piled on this film layer to prevent the floating; 100 $\mathrm{ml}$ of each OP insecticide solution (5 ppm in distilled water) was poured into the prepared column at room temperature. The flow-through aqueous solution was collected through a cone funnel and refilled back into the column for seven batches; $1 \mathrm{ml}$ of sample from each batch was centrifuged at $20,627 \mathrm{~g}$ for $15 \mathrm{~min}$ at $4^{\circ} \mathrm{C}$ and the supernatant was analysed by high-performance liquid chromatography (HPLC, described in section 2.8) to evaluate the $\mathrm{OP}$ insecticide residues.

\subsection{Analysis of OP insecticides by HPLC}

HPLC was used to determine the residue of OP pesticides after absorption by modified bentonite following the procedure of Anh et al [30]. Samples (1 ml) were centrifuged at 20,627 $g$ for $15 \mathrm{~min}$, filtered using a VeriPure Nylon Syringe Filter $(0.2 \mu \mathrm{m}$ pore size; Vertical ${ }^{\circledR}$ ) and transferred to $2 \mathrm{ml}$ HPLC vials. An Agilent HPLC system (series 1100; Agilent) equipped with a VertiSep ${ }^{\mathrm{TM}}$ AQS reversed-phase (C18) column (4.6 mm $\times$ $150 \mathrm{~mm}, 5 \mu \mathrm{m}$; Vertical ${ }^{\circledR}$ ) was used for all analyses. Samples were analysed by applying a gradient of 20-80\% acetonitrile ( 0 and $4 \mathrm{~min}, 20 \%$; 4 and $12 \mathrm{~min}, 80 \%$; 12 and $17 \mathrm{~min}, 20 \%$ ) for $20 \mathrm{~min}$ at a constant flow rate of $1 \mathrm{ml} \mathrm{min}^{-1}$. Degraded pesticides and pesticide residues were identified and quantified by means of authentic standards (chlorpyriphos, profenofos, methyl parathion and dimethoate).

\section{Results and discussion}

\subsection{Two steps modification of bentonite by $\mathrm{NaCl}$ and $\mathrm{BBrCl}$ and characterization by SEM and FTIR}

The modification of bentonite by $\mathrm{NaCl}$ and $\mathrm{BBrCl}$ aimed to enhance the absorption capacity of the original bentonite. Firstly, Ca-bentonite (commercial bentonite) or non-swelling bentonite was converted to Na-bentonite or swelling bentonite form [31] via the exchange of original $\mathrm{Ca}^{2+}$ by $\mathrm{Na}^{+}$in $\mathrm{NaCl}$ solution. Later, $\mathrm{Na}$-bentonite was converted to $\mathrm{BBr}$-bentonite (figure 2b) when $\mathrm{BBr}^{+}$displaced $\mathrm{Na}^{+}$in $\mathrm{Na}$-bentonite. The
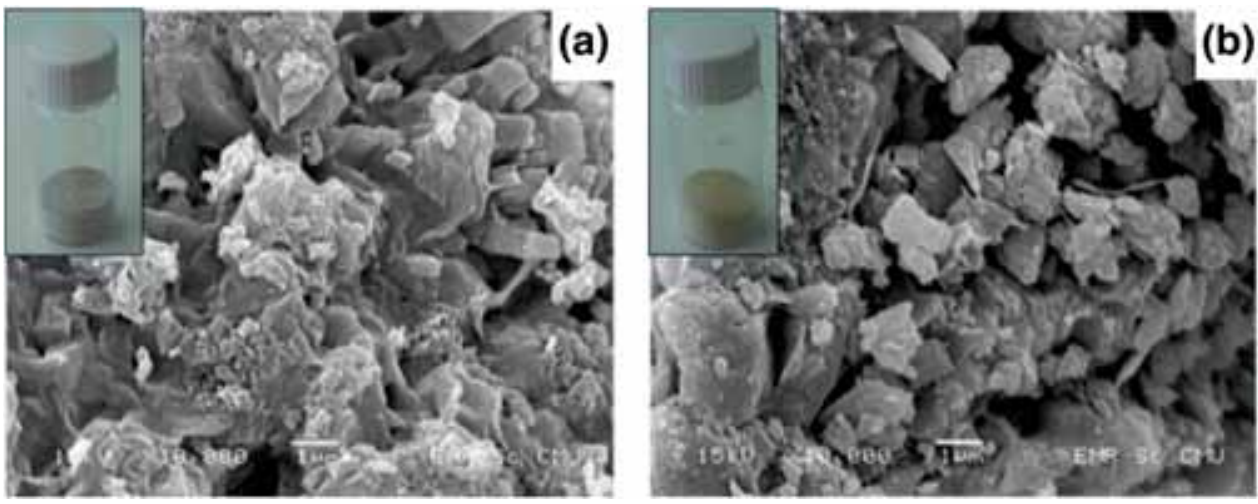

Figure 2. Typical SEM images of (a) Na-bentonite and (b) BBr-bentonite. Top-left insets are (a) grey Na-bentonite and (b) yellow BBr-bentonite powder samples. 


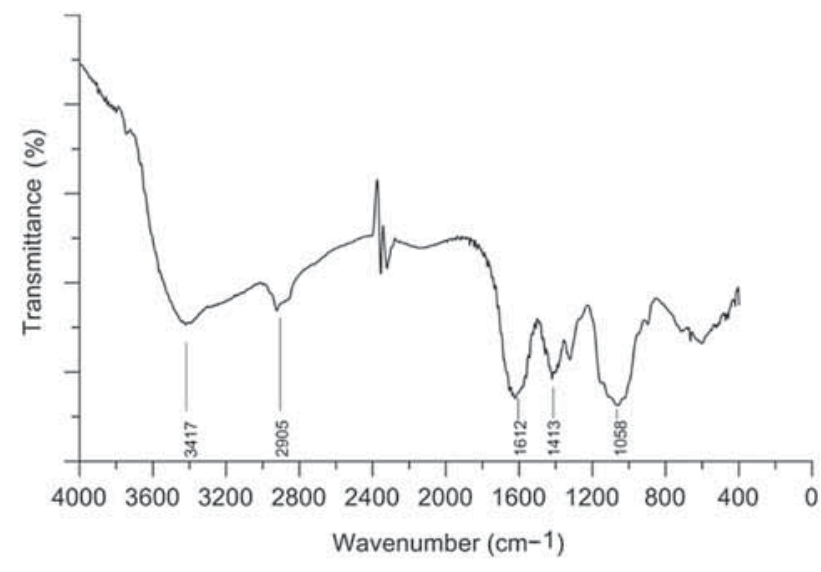

Figure 3. FTIR spectrum of sodium carboxymethyl chitosan.

Na-bentonite was grey whereas $\mathrm{BBr}$-bentonite was yellow (figure $2 a$ and $b$ ). At the magnification of $\times 10000$, the SEM image of Na-bentonite shows a matrix composed of polymorphic blocks and some cavities or the matrix was not hollow. This was similar in comparison to the SEM image of the microstructure of Na-bentonite in Danaja et al [32]. However, SEM image of BBr-bentonite shows a porous matrix composed of dispersed amorphous blocks. SEM image of $\mathrm{BBr}$-bentonite in figure $2 \mathrm{~b}$ is similar to the SEM image in the report about surficial morphology of BBr-modified bentonite of Rytwo et al [14]. BBr-bentonite was formed when $\mathrm{BBr}^{+}$displaced $\mathrm{Na}^{+}$and the basal spacings between bentonite sheets were increased $[14,15]$. Furthermore, the intercalation of $\mathrm{BBr}^{+}$into bentonite structure changed the originally exchangeable cations, i.e., $\mathrm{Na}^{+}$and $\mathrm{Ca}^{2+}$, and generated more hydrophilic sites on the clay surface, which enhanced the interaction between $\mathrm{BBr}$-bentonite and tested $\mathrm{OP}$ insecticides. In addition, $\mathrm{BBr}^{+}$cations were not desorbed from stable $\mathrm{BBr}$ bentonite complexes [15].

\subsection{Characterization of synthesized CMCh by FTIR}

The CMCh material was used in this work due to its flexible water solubility over a wide $\mathrm{pH}$ range and temperature in comparison with native chitosan [33,34]. Under experimental conditions, commercial shrimp chitosan was converted to sodium salt CMCh form. The use of domestic shrimp chitosan was also significant in terms of low cost, especially because Thailand is a chitosan-exporting country. A typical FTIR spectrum of synthesized CMCh (figure 3) reveals characteristic peaks at $3417 \mathrm{~cm}^{-1}$ (O-H stretch), $2905 \mathrm{~cm}^{-1}$ (C-H stretch), $1574-1650$ and $1413 \mathrm{~cm}^{-1}$ (-COONa, $-\mathrm{NH}_{2}$ and $=\mathrm{CH}_{2}$ with sodium $\mathrm{CMCh}$, respectively) and $1058 \mathrm{~cm}^{-1}$ (C-O stretch). These FTIR results are in agreement with previous reports of $\mathrm{CMCh}$ analysis from different shrimp sources [33,35-37].

\subsection{Characterization of CMCh and Na-Bentonite-CMCh and BBr-Bentonite-CMCh films by SEM and FTIR}

Three types of films were fabricated for OP insecticides filtration test. SEM and FTIR results revealed the relation between the films morphologies and chemical components in the absorptivity tests of OP insecticides. Figure $4 \mathrm{a}, \mathrm{c}$ and e shows the morphologies of $\mathrm{CMCh}, \mathrm{Na}$-bentonite-CMCh and $\mathrm{BBr}$-bentonite-CMCh films, and figure $4 \mathrm{~b}, \mathrm{~d}$ and $\mathrm{f}$ depicts FTIR characteristics of these respective films. The CMCh film was transparent and colourless (inset in figure 4a) with smooth surface at magnification of $\times 2000$ (figure 4a). The $\mathrm{Na}$-bentonite-CMCh film was opaque grey, whereas $\mathrm{BBr}-$ bentonite-CMCh film was opaque yellow (insets in figure $4 \mathrm{c}$ and e, respectively). At the magnification of $\times 3000$, their surfaces were rough; however, $\mathrm{BBr}$-bentonite-CMCh film surface visually showed the density of blocks to be about three times higher than the surficial block density of Na-bentonite$\mathrm{CMCh}$ film (figure $4 \mathrm{e}$ and $\mathrm{c}$, respectively). Interestingly, the surface morphologies by SEM analysis of these films were different but their FTIR spectra were almost congruent to the FTIR of CMCh powder (figure 3). In the case of CMCh film, all FTIR peaks in figure $4 \mathrm{~b}$ were obtuse but FTIR spectra of Na-bentonite-CMCh (figure $4 \mathrm{~d}$ ) and $\mathrm{BBr}$-bentonite- $\mathrm{CMCh}$ films (figure 4f) both revealed clear characteristic peaks of $\mathrm{CMCh}$ powder as in figure 3 . The different shapes of congruent peaks in FTIR spectra of different film types might be the result of sample preparation, where some samples needed heat treatment. The congruence between FTIR results of modified bentonite-CMCh films and $\mathrm{CMCh}$ powder implies that in both Na-bentonite-CMCh and BBr-bentonite-CMCh films, the $\mathrm{CMCh}$ component intercalated and enfolded all modified bentonite components tightly and flexibly.

\subsection{Batch filtration to remove OP insecticides using modified bentonite-CMCh films}

BBr-bentonite-CMCh and Na-bentonite-CMCh films (insets in figure $4 \mathrm{e}$ and $\mathrm{c}$, respectively) were intensively used for filtration to remove $5 \mathrm{ppm}$ OP insecticides from spiked water samples. This work was carried out based on our previous and selected reports elsewhere about: (i) the diverse absorptivity of bentonite to various OP insecticides [6,7,9,38-41]; (ii) the large water solubility of $\mathrm{CMCh}$ over a wide range of $\mathrm{pH}$ from 4 to 11 and temperature from 10 to $50^{\circ} \mathrm{C}$, which is not influenced by ionic strength in aqueous solution $[42,43]$; (iii) the non-toxic nature of both bentonite and CMCh material to humans and the environment $[19,34,44,45]$. Apparently, the $\mathrm{BBr}$-bentonite-CMCh film could absorb OP insecticides in water. With the design of filtration columns that contained $3 \mathrm{~g}$ of BBr-bentonite-CMCh film, profenofos, chlorpyrifos, methyl parathion and dimethoate were removed from the spiked water after seven batches at the rate of 42, 39, 24 and $20 \%$, respectively (figure $5 \mathrm{a}$ ). The Na-bentonite-CMCh film also removed these OP insecticides profenofos, chlorpyrifos, methyl parathion and dimethoate at the rate of 16 , 

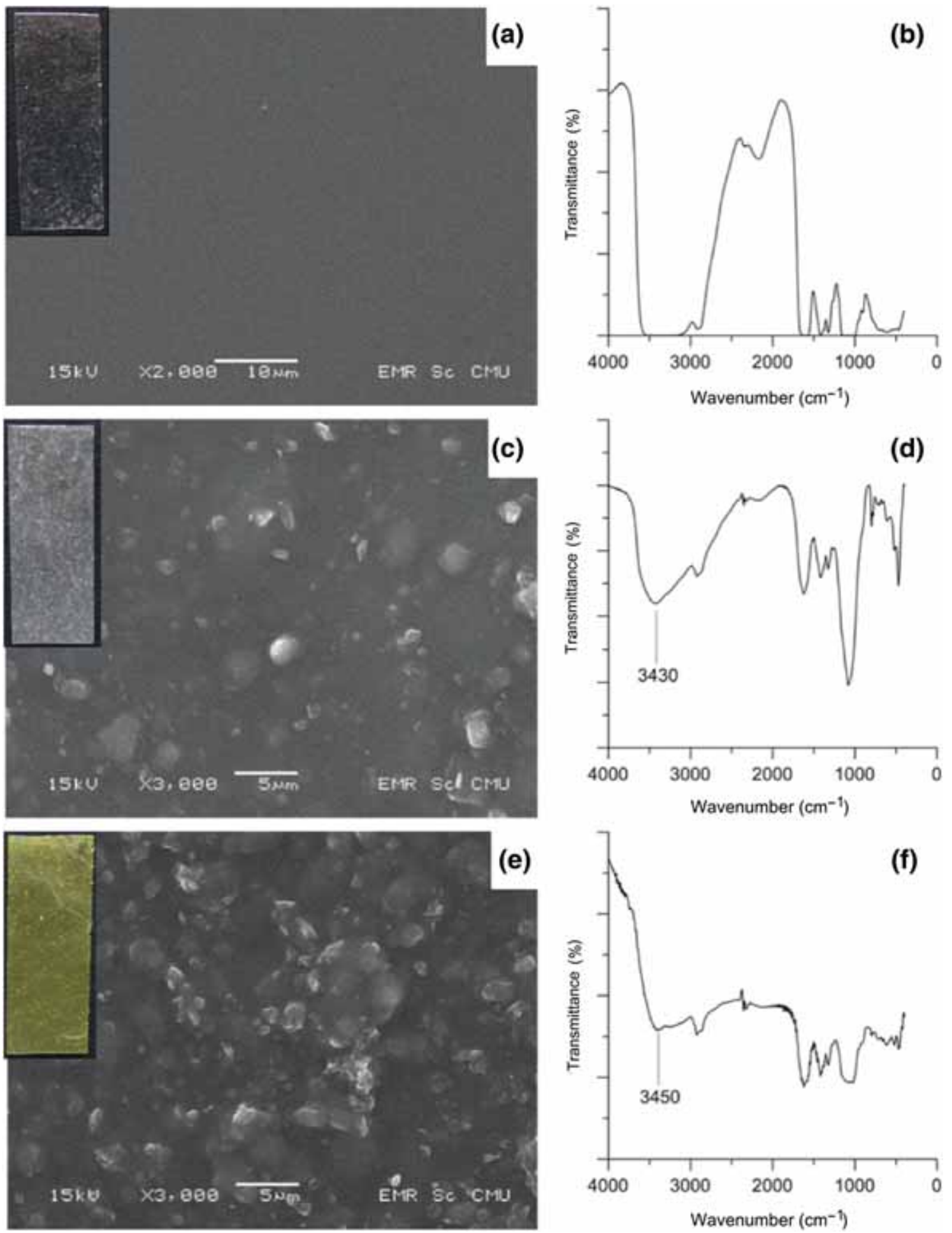

Figure 4. Typical (a, c and e) SEM images and (b, d and $\mathbf{f})$ FTIR spectra of CMCh, Na-bentonite-CMCh and BBrbentonite-CMCh films. Inset in SEM images are (a) $\mathrm{CMCh}$, (c) Na-bentonite-CMCh and (e) BBr-bentonite-CMCh film samples.

16,11 and $12 \%$ after seven batches of filtration, respectively (figure $5 b$ ). In most of the previous works, modified bentonite was dispersed in aqueous solution of OP insecticides for the absorption study. Chlorpyrifos and methyl parathion were absorbed when modified bentonite in cationic micelles form was suspended in insecticides solution $[9,38,46]$. The 

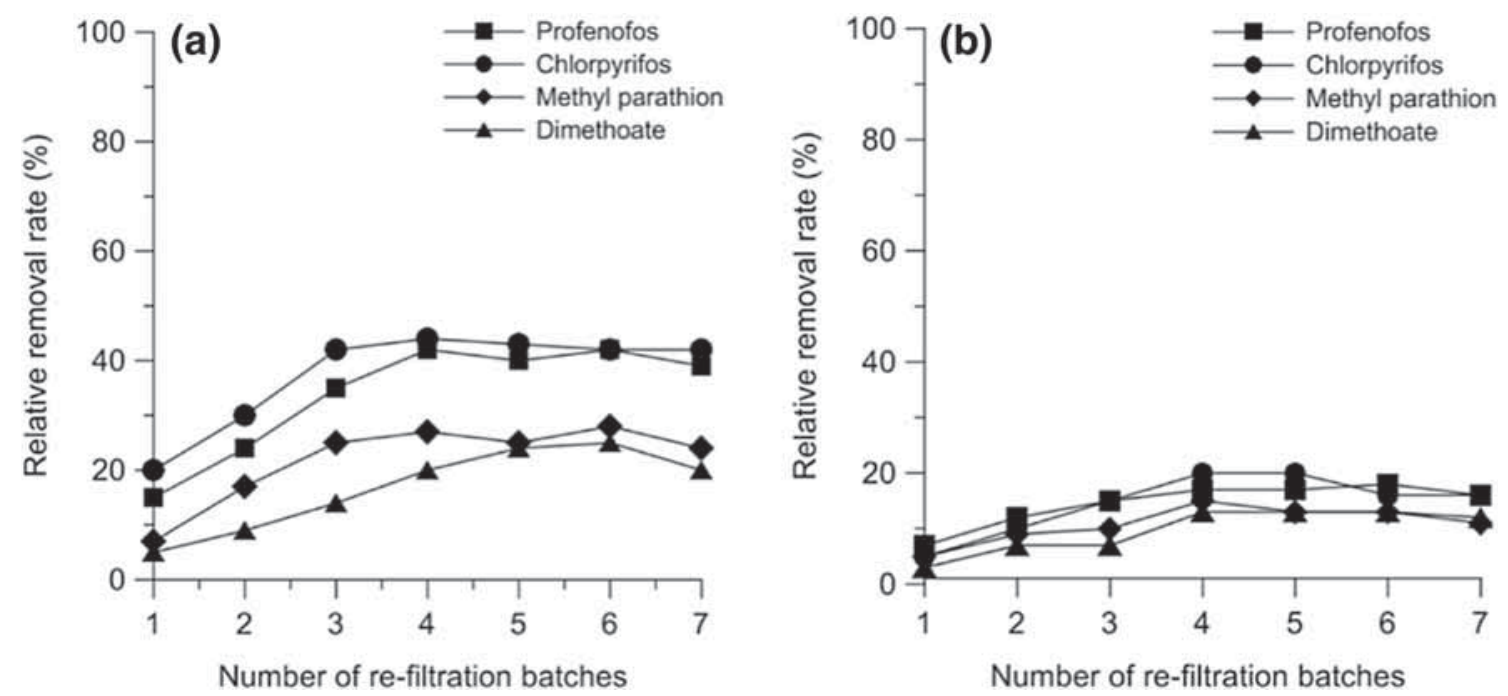

Figure 5. Removal rate of $\mathrm{OP}$ insecticides by modified bentonite-CMCh films by batch filtration. Data points are means of three parallel measurements $(\mathrm{SD}<15 \%$ ). Filtration mode using (a) $\mathrm{CMCh}-\mathrm{BBr}$-bentonite film and (b) $\mathrm{CMCh}-\mathrm{Na}-$ bentonite film.

adsorption of profenofos and dimethoate used soils and clays as adsorbents in aqueous solution [41,47]. Dispersed bentonite was also applied to remove various herbicides and pesticides in aqueous solution $[6,40,48]$. Numerous works proved the absorptivity of modified bentonite to the various insecticides. However, the collection of the insecticideabsorbing bentonite remained technically as a 'bottle neck' for field application. It was difficult to separate the insecticideabsorbing bentonite in field application. Apparently, this work showed that OP insecticides were partly removed from contaminated water via batch filtration using modified bentonite films. Thus, OP-insecticide-absorbing film can be simply collected and replaced by new film materials.

The higher removal rate to $\mathrm{OP}$ insecticides of $\mathrm{BBr}$ bentonite-CMCh film than that of Na-bentonite-CMCh film was deduced from the larger basal spacing between structural sheets of BBr-bentonite than that of Na-bentonite [17]. The absorption mechanism of tested OP insecticides possibly also followed the 'C-type' $[15,49]$. This described that the increase of the organic content alkaloid berberine in clays enhanced the absorption of diluted organic pesticide, e.g., metolachlor. Noticeably, there are possible hydrogen bond acceptors $\left(=\mathrm{O},-\mathrm{Cl},-\mathrm{Br},-\mathrm{NO}_{2}\right)$ in structures of tested $\mathrm{OP}$ insecticides, which are about 4, 5, 6 and 5 sites for profenofos, chlorpyrifos, methyl parathion and dimethoate, respectively (figure 1). Hence, water bridges can be formed between berberine and those insecticides to enhance the absorptivity of BBr-bentonite-CMCh film to tested OP insecticides.

Additionally, at the same concentration of $5 \mathrm{ppm}$ in water, tested OP insecticides removal rate was in the order profenofos $>$ chlorpyrifos $>$ methyl parathion $>$ dimethoate. This result is in accordance with the soil organic carbon water partition coefficient $\left(K_{\mathrm{oc}}\right)$ value of related insecticides, where 'higher $K_{\mathrm{oc}}$ values correlate to low-mobility organic chemicals while lower $K_{\text {oc }}$ values correlate to more mobile organic chemicals' [50]. $K_{\text {oc }}$ in clay soils of profenofos, chlorpyrifos, methyl parathion and dimethoate takes values from 869 to 3162,4381 to 6129,366 to 1516 and 5.2 to 50 , respectively [51,52]. As regards $K_{\mathrm{oc}}$ values, it was assumed that profenofos and chlorpyrifos were less mobile in modified bentonite or they were captured tightly by modified bentonite, whereas methyl parathion and dimethoate were more mobile in modified bentonite. This also reflected the higher profenofos and chlorpyrifos removal rates than methyl parathion and dimethoate removal rates by using modified bentonite.

\subsection{Influence of film form and its microstructure on the absorption of tested OP insecticides}

In this work, the modified bentonite was immobilized in $\mathrm{CMCh}$ via in situ polymerization of $\mathrm{CMCh}$ to form the modified bentonite-CMCh film material. Due to the water solubility property of $\mathrm{CMCh}$, dispersal of modified bentonite inside the polymerized $\mathrm{CMCh}$ matrix is uniform when both materials can be mixed well before the casting of the film. The immobilized modified bentonite not only functions as an OP insecticide absorbent but also enhances the physical property of the hybrid film. FTIR spectra of BBr-bentonite-CMCh and Na-bentonite-CMCh film show peaks at 3450 and $3430 \mathrm{~cm}^{-1}$, respectively, representing the vibration bands of the $\mathrm{N}-\mathrm{H}$ bonded $\mathrm{O}-\mathrm{H}$ between film components, e.g., hydroxyl group in hydroxylated silicate layers of bentonite might form hydrogen bonds to amine group in $\mathrm{CMCh}$. The intercalation of $\mathrm{BBr}^{+}$generated more cationic charge of modified bentonite, which interacted with anionic carboxyl group in $\mathrm{CMCh}$. Thus, the film formation might be a result of strong electrostatic interaction between modified bentonite and $\mathrm{CMCh}$ 

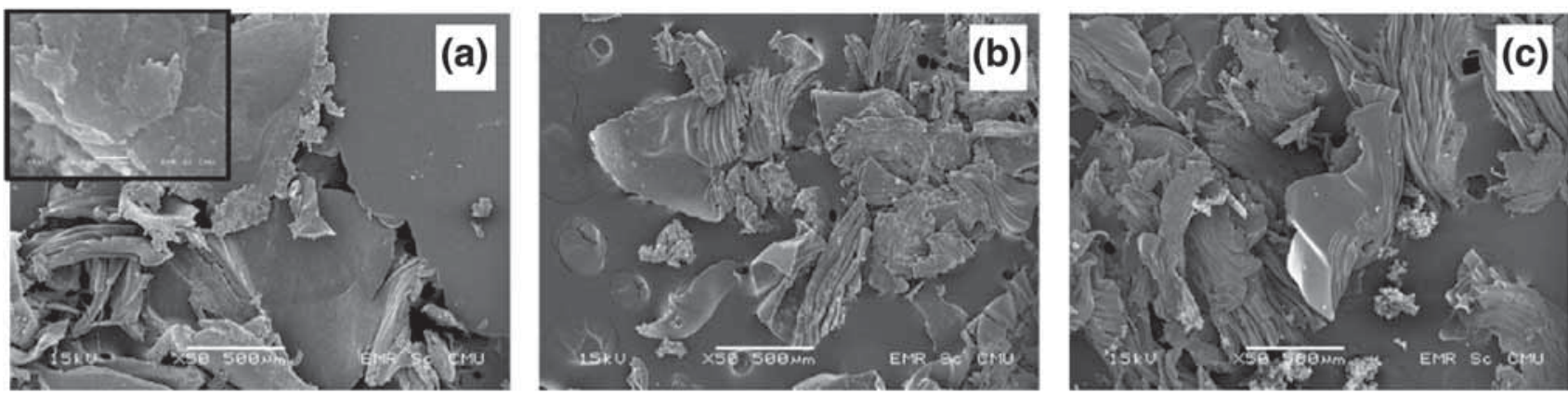

Figure 6. SEM images of surfaces of (a) profenofos-absorbing BBr-bentonite-CMCh, (b) Na-bentonite-CMCh and (c) CMCh film after three batches of filtration. Inset in $\mathbf{a}$ is the SEM of BBr-bentonite-CMCh film at magnification of $\times 20,000$.

components. The addition of $10 \%(\mathrm{v} / \mathrm{v}) \mathrm{BBr}$-bentonite or Nabentonite increased the tension strength of both $\mathrm{CMCh}-\mathrm{BBr}$ bentonite and $\mathrm{CMCh}-\mathrm{Na}$-bentonite by approximately $15 \%$ in comparison with $\mathrm{CMCh}-$ bentonite, respectively (data not shown). Potassium persulphate-modified bentonite increased the tensile strength and restricted the degradation of the relevant chitosan-bentonite nanocomposites [26]. Another work showed that the addition of 3\% (v/v) Na-bentonite into chitosan acetate solution also increased the stiffness and strength of the final film by $100 \%$ [53]. Thus, the modified bentonite-CMCh film form is easy to handle for absorption procedures.

A typical BBr-bentonite-CMCh film is revealed in figure $6 \mathrm{a}$ with sheets, and gaps between sheets. The inset image shows a structural 'layer-upon-layer' (top left inset in figure 6a). However, Na-bentonite-CMCh (figure 6b) and CMCh films (figure 6c) mostly composed of folding and twisting blocks and less space between these blocks. SEM results suggested that aqueous OP insecticide solution fluently flowed through the $\mathrm{BBr}$-bentonite-CMCh film. The contact surface area between the tested $\mathrm{OP}$ insecticide solutions and $\mathrm{BBr}$-bentonite- $\mathrm{CMCh}$ film (figure 6a) was obviously larger in comparison with that of Na-bentonite-CMCh film (figure 6b). Therefore, tested OP insecticide molecules probably interact at higher frequency with absorptive material in case of $\mathrm{BBr}$-bentonite-CMCh film and it contributed to its higher OP insecticides removal rate than that of Na-bentonite-CMCh film.

\section{Conclusions}

A film composed of berberine-modified bentonite and $\mathrm{CMCh}$ is simply fabricated and applied for OP insecticides removal. The modified bentonite in the film can absorb OP insecticides from aqueous solution via rebatch filtration remarkably. The commercial bentonite clay, natural berberine powder and chitosan from shrimp are non-toxic and low-cost products; therefore, it is promising to develop an economic, eco-friendly and suitable film material to remove agricultural insecticide residues in agricultural run-off water zones.

\section{Acknowledgements}

We are thankful to the Department of Chemistry, Faculty of Science, and Microscope Unit of Chiang Mai University for HPLC analysis and SEM analysis supports.

\section{References}

[1] Peng X, Luan Z, Zhang H and Tian B 2005 J. Environ. Sci. Health A Tox. Hazard Subst. Environ. Eng. 401055

[2] Yadanaparthi S K, Graybill D and von Wandruszka R 2009 J. Hazard Mater. 1711

[3] Turan N G and Ozgonenel O 2013 Sci. World J. 2013342628

[4] Naseem N and Tahir S S 2001Water Res. 353982

[5] Barati A, Asgari M, Miri T and Eskandari Z 2013 Environ. Sci. Pollut. Res. Int. 206242

[6] Davies J E and Jabeen N 2003 J. Incl. Phenom. Macrocycl. Chem. $\mathbf{4 6} 57$

[7] Tha-in S, Dau H A and Dumri K 2013 Int. J. Environ. Sci. Dev. 4415

[8] Mircioiu C, Voicu V A, Ionescu M, Miron D S, Radulescu F S and Nicolescu A C 2013 Toxicol. Lett. 21999

[9] Bowman B T and Sans W W 1977 Soil Sci. Soc. Am. J. 41514

[10] Wiles M C, Huebner H J, McDonald T J, Donnelly K C and Phillips T D 2005 Chemosphere $\mathbf{5 9} 1455$

[11] Ake C L, Wiles M C, Huebner H J, McDonald T J, Cosgriff D, Richardson M B et al 2003 Chemosphere 51835

[12] Pal O R and Vanjara A K 2001 Sep. Purif. Technol. 24167

[13] Celis R, Trigo C, Facenda G, Hermosin M C and Cornejo J 2007 J. Agric. Food Chem. $\mathbf{5 5} 6650$

[14] Rytwo G, Varman H, Bluvshtein N, König T N, Mendelovits A and Sandler A 2011 Appl. Clay Sci. 5143

[15] Rytwo G, Gonen Y and Afuta S 2008 Appl. Clay Sci. 4147

[16] Rojsanga P, Gritsanapan W and Suntornsuk L 2006 Med. Princ. Pract. 15373

[17] Chulkov A N, Deineka V I, Tikhova A A, Vesentzev A I and Deineka L A 2012 Russ. J. Phys. Chem. A 86429

[18] Giri T K, Thakur A, Alexander A, Badwaik A H and Tripathi D K 2012 Acta Pharm. Sin. B 2439

[19] Upadhyaya L, Singh J, Agarwal V and Tewari R P 2013 Carbohydr. Polym. 91452 
[20] Vanamudan A, Bandwala K and Pamidimukkala P 2014 Int. J. Biol. Macromol. 69506

[21] Liu Q, Yang B, Zhang L and Huang R 2015 Int. J. Biol. Macromol. 721129

[22] Nesic A R, Velickovic S J and Antonovic D G 2012 J. Hazard Mater. 209256

[23] Celis R, Adelino M, Hermosin M C and Cornejo J $2012 \mathrm{~J}$. Hazard Mater. 20967

[24] Guo J, Chen S, Liu L, Li B, Yang P, Zhang L et al $2012 \mathrm{~J}$. Colloid Interface Sci. 38261

[25] Wang X, Du Y, Yang J, Tang Y and Luo J 2008 J. Biomed. Mater. Res. A 84384

[26] Tan W, Zhang Y, Szeto Y and Liao L 2008 Compos. Sci. Technol. 682917

[27] WHO 2004 The WHO recommended classification of pesticides by hazard and guidelines to classification (Geneva: International Program on Chemicals Safety)

[28] Panuwet P, Siriwong W, Prapamontol T, Ryan P B, Fiedler N, Robson M G et al 2012 Environ. Sci. Policy 1772

[29] Wanwimolruk S, Kanchanamayoon O, Boonpangrak S and Prachayasittikul V 2015 Environ. Health Prev. Med. 20204

[30] Anh D H, Cheunrungsikul K, Wichitwechkarn J and Surareungchai W 2011 Biotechnol. J. 6565

[31] Kogel J E, Trivedi N C, Barker J M and Krukowski S T 2006 Industrial minerals and rocks-commodities, markets, and uses (New York: Society for Mining: Metallurgy, and Exploration Press)

[32] Dananaj I, Frankovská J and Janotka I 2005 Appl. Clay Sci. 28 223

[33] Chen X G and Park H J 2003 Carbohydr. Polym. 53355

[34] Jimtaisong A and Saewan N 2014 Int. J. Cosmet. Sci. 3612

[35] Brugnerotto J, Lizardi J, Goycoolea F M, Argüelles-Monal W, Desbrières J and Rinaudo M 2001 Polymer 423569
[36] Shigemasa Y, Matsuura H, Sashiwa H and Saimoto H 1996 Int. J. Biol. Macromol. 18237

[37] Jaidee A, Rachtanapun P and Luangkamin S 2012 Adv. Mater. Res. 506158

[38] Suciu N A and Capri E 2009 J. Environ. Sci. Health B 44 525

[39] Shabeer T P A, Saha A, Gajbhiye V T, Gupta S, Manjaiah K M and Varghese E 2015 Water Air Soil Pollut. 2261

[40] Ye P and Lemley A T 2008 J. Agric. Food Chem. 5610200

[41] Spliid N H, Helweg A and Heinrichson K 2006 Chemosphere 652223

[42] Pang H T, Chen X G, Park H J, Cha D S and Kennedy J F 2007 Carbohydr. Polym. 69419

[43] Thanou M, Verhoef J C and Junginger H E 2001 Adv. Drug Deliv. Rev. 52117

[44] Williams L B and Haydel S E 2010 Int. Geol. Rev. 52745

[45] Haydel S E, Remenih C M and Williams L B 2008 J. Antimicrob. Chemother. 61353

[46] Seger M R and Maciel G E 2006 Environ. Sci. Technol. 40 797

[47] Kanazawa J 1989 Environ. Toxicol. Chem. 8477

[48] Shabeer T P, Saha A, Gajbhiye V T, Gupta S, Manjaiah K M and Varghese E 2014 Environ. Technol. 352619

[49] Sparks D L 1995 Environmental soil chemistry (London: Academic Press)

[50] EPA U S 1996 Soil screening guidance: technical background document EPA/540/R-95/128

[51] https://pubchem.ncbi.nlm.nih.gov/

[52] Howard P H 1991 Handbook of environmental fate and exposure data for organic chemicals (Florida: Taylor and Francis Group; CRC Press)

[53] Giannakas A, Grigoriadi K, Leontiou A, Barkoula N M and Ladavos A 2014 Carbohydr. Polym. 108103 